\title{
Activation of Guanylate Cyclase-C Attenuates Stretch Responses and Sensitization of Mouse Colorectal Afferents
}

\author{
Bin Feng, ${ }^{1}$ Michael E. Kiyatkin, ${ }^{1}$ Jun-Ho La, ${ }^{1}$ Pei Ge, ${ }^{2}$ Robert Solinga, ${ }^{2}$ Inmaculada Silos-Santiago, ${ }^{2}$ \\ and Gerald F. Gebhart ${ }^{1}$ \\ ${ }^{1}$ Center for Pain Research, Department of Anesthesiology, School of Medicine, University of Pittsburgh, Pittsburgh, Pennsylvania 15213 and ${ }^{2}$ Ironwood \\ Pharmaceuticals, Cambridge, Massachusetts 02142
}

Irritable bowel syndrome (IBS) is characterized by altered bowel habits, persistent pain and discomfort, and typically colorectal hypersensitivity. Linaclotide, a peripherally restricted 14 aa peptide approved for the treatment of IBS with constipation, relieves constipation and reduces IBS-associated pain in these patients presumably by activation of guanylate cyclase-C (GC-C), which stimulates production and release of cyclic guanosine monophosphate (cGMP) from intestinal epithelial cells. We investigated whether activation of GC-C by the endogenous agonist uroguanylin or the primary downstream effector of that activation, cGMP, directly modulates responses and sensitization of mechanosensitive colorectal primary afferents. The distal $2 \mathrm{~cm}$ of mouse colorectum with attached pelvic nerve was harvested and pinned flat mucosal side up for in vitro single-fiber recordings, and the encoding properties of mechanosensitive afferents (serosal, mucosal, muscular, and muscular-mucosal; M/M) to probing and circumferential stretch studied. Both cGMP (10 -300 $\mu \mathrm{M})$ and uroguanylin (1-1000 nм) applied directly to colorectal receptive endings significantly reduced responses of muscular and M/M afferents to stretch; serosal and mucosal afferents were not affected. Sensitized responses (i.e., increased responses to stretch) of muscular and M/M afferents were reversed by cGMP, returning responses to stretch to control. Blocking the transport of cGMP from colorectal epithelia by probenecid, a mechanism validated by studies in cultured intestinal T84 cells, abolished the inhibitory effect of uroguanylin on M/M afferents. These results suggest that GC-C agonists like linaclotide alleviate colorectal pain and hypersensitivity by dampening stretchsensitive afferent mechanosensitivity and normalizing afferent sensitization.

\section{Introduction}

Irritable bowel syndrome (IBS) is a prevalent functional disorder characterized by altered bowel habits and abdominal pain, the latter of which is difficult to manage. Growing evidence reveals that primary afferent drive from the colorectum maintains the pain and associated colorectal hypersensitivity in IBS. For example, intrarectal instillation of a local anesthetic relieves pain and reduces expanded areas of abdominal referral in IBS patients (Verne et al., 2003, 2005) and colorectal hypersensitivity in rats (Zhou et al., 2008). Linaclotide, a 14 aa peptide acting locally within the gastrointestinal tract, has been reported to significantly reduce abdominal pain in IBS patients with constipation (IBS-C) (Johnston et al., 2010; Chey et al., 2012; Rao et al., 2012).

Linaclotide is believed to be effective in IBS-C by activation of guanylate cyclase-C (GC-C) located on the luminal/apical sur-

Received Oct. 30, 2012; revised April 29, 2013; accepted May 2, 2013.

Author contributions: B.F., I.S.-S., and G.F.G. designed research; B.F., M.E.K., J.-H.L., P.G., and R.S. performed research; B.F., I.S.-S., and G.F.G. contributed unpublished reagents/analytic tools; B.F., M.E.K., J.-H.L., P.G., R.S., and G.F.G. analyzed data; B.F., I.S.-S., and G.F.G. wrote the paper.

This work is supported by National Institutes of Health Grant R01 DK093525 (G.F.G.); contract \#SRA-4644 from Ironwood Pharmaceuticals, Cambridge, MA; and Forest Laboratories, Jersey City, NJ. We thank Michael Burcham for assistance in preparation of figures.

B.F. was supported in part by contract \#SRA-4644 from Ironwood Pharmaceuticals, Cambridge, MA, and Forest Laboratories, Jersey City, NJ during the course of this study.

Correspondence should be addressed to Dr. Bin Feng, Center for Pain Research, University of Pittsburgh, W1402 BST, 200 Lothrop Street, Pittsburgh, PA 15213. E-mail: fengb@upmc.edu.

DOI:10.1523/JNEUROSCI.5114-12.2013

Copyright $\odot 2013$ the authors $\quad 0270-6474 / 13 / 339831-09 \$ 15.00 / 0$ face of intestinal epithelial cells (Swenson et al., 1996) to cause release of cyclic guanosine monophosphate (cGMP) from their basolateral membrane. Like the endogenous agonist uroguanylin (UGN-A), linaclotide activates GC-C and enhances intestinal secretion (and relieves constipation) by increasing the synthesis of cGMP in intestinal epithelia which subsequently (1) enhances chloride and bicarbonate secretion through the cystic fibrosis transmembrane conductance regulator (CFTR), (2) inhibits luminal sodium absorption, and (3) activates other CFTRindependent mechanisms (Bharucha and Linden, 2010; Bryant et al., 2010).

In contrast to its effect on secretion, the antihyperalgesic mechanism(s) of linaclotide is unknown; because linaclotide normalizes hypersensitive responses to noxious colorectal distension, the mechanism likely involves modulation of colorectal afferents (Eutamene et al., 2010). Sensory information from the distal colorectum is transmitted to the spinal cord by lumbar splanchnic (LSN) and pelvic (PN) nerve pathways. The majority of LSN mechanosensitive afferents are of the serosal and mesenteric classes that respond to probing of their receptive fields. Colorectal afferents that encode stretch/distension (stretchsensitive afferents) predominate in the PN pathway, consistent with evidence that responses to colorectal distension are unaffected after LSN transection but abolished after PN transection (Kyloh et al., 2011).

A recent study suggested that cGMP is actively transported out of intestinal epithelial cells in close proximity to extrinsic colo- 
rectal afferent endings in response to GC-C agonists (GCCAs), including linaclotide, and this transport is inhibited by the anion transporter inhibitor probenecid (Silos-Santiago et al., unpublished observations). Thus, cGMP may act directly on colorectal afferents to reduce mechanosensory encoding and attenuate stretch/distension-induced pain in IBS patients (Bouin et al., 2002). We tested this hypothesis, first by examining the effects of cGMP on responses to mechanical stimuli and acute sensitization of PN colorectal afferents. Second, we examined the effects of the endogenous GCCA uroguanylin on colorectal afferent mechanosensitivity in the absence and presence of probenecid to confirm that GCCA-induced attenuation of afferent responses depended upon cGMP transport from epithelial cells. The efficacy of probenecid was documented using cultured intestinal T84 cells, which express GC-C. Finally, we examined the effects of cGMP on sensitized colorectal afferents in a model of persistent colorectal hypersensitivity. Portions of these data were reported in abstract form (Feng et al., 2012a).

\section{Materials and Methods}

All experiments were approved by the University of Pittsburgh Institutional Animal Care and Use Committee.

\section{In vitro mouse colon-pelvic nerve preparation}

As previously described (Feng et al., 2012c), male mice (C57BL/6, 6-8 weeks old, 20-30 g; Taconic) were killed via $\mathrm{CO}_{2}$ inhalation followed by exsanguination after perforating the right atrium. The distal colorectum with attached PN was dissected and transferred to ice-cold Krebs' solution bubbled with carbogen $\left(95 \% \mathrm{O}_{2}, 5 \% \mathrm{CO}_{2}\right)$. The colorectum was opened longitudinally, pinned flat mucosal side up in a tissue chamber, and the PN extended into an adjacent recording chamber filled with paraffin oil. The tissue chamber was superfused with a modified Krebs' solution containing the following (in $\mathrm{mm}$ ): $117.9 \mathrm{NaCl}, 4.7 \mathrm{KCl}, 25$ $\mathrm{NaHCO}_{3}, 1.3 \mathrm{NaH}_{2} \mathrm{PO}_{4}, 1.2 \mathrm{MgSO}_{4}, 7 \mathrm{H}_{2} \mathrm{O}, 2.5 \mathrm{CaCl}_{2}, 11.1$ D-glucose, 2 butyrate, and 20 acetate at a temperature of $\sim 34^{\circ} \mathrm{C}$ to which was added nifedipine $(4 \mu \mathrm{M})$ and indomethacin $(3 \mu \mathrm{M})$. The $\mathrm{PN}$ was teased into fine bundles ( $\sim 10 \mu \mathrm{m}$ thickness) for single-fiber recording.

\section{Stimulus-response functions}

As previously described (Feng and Gebhart, 2011), mechanosensitive colorectal afferents were classified as serosal, muscular, mucosal, or muscular-mucosal (M/M) based upon responses to probing with calibrated nylon monofilaments $(0.4,1$, and $1.4 \mathrm{~g}$ force), mucosal stroking (10 mg of force), and stretch. Muscular and $\mathrm{M} / \mathrm{M}$ afferents both respond to stretch and their stimulus-response functions (SRFs) to circumferential stretch were generated using a servo-controlled force actuator (Aurora Scientific) as described previously (Feng and Gebhart, 2011). Custommade claws $(\sim 1 \mathrm{~mm}$ interval) were inserted along the antimesenteric edge of the colorectum to permit homogeneous, circumferential stretch by a slow ramped force $(0-170 \mathrm{mN}$ at $5 \mathrm{mN} / \mathrm{s})$ corresponding to intraluminal pressures of $0-45 \mathrm{mmHg}$ (Feng et al., 2010).

Serosal and mucosal afferents do not respond to stretch, and SRFs were generated using ascending steps of probing forces $(1-80 \mathrm{mN}, 5 \mathrm{~s}$ duration, $25 \mathrm{~s}$ interstimulus interval) applied with a $\phi 1 \mathrm{~mm}$ nylon monofilament (\#6.45; Stoelting) driven by the servo-controlled force actuator, thus ensuring precise and reproducible stimulation of the receptive field. The diameter of the probe was selected to approximately match receptive field size, which is typically $1 \mathrm{~mm}^{2}$ (Feng and Gebhart, 2011), and sharp edges rounded to reduce stress concentration.

Compliance was quantified by measuring colorectal circumference during stretch. Colorectal deformation during stretch was recorded through the stereo dissection microscope using a CCD camera; images were extracted every $2 \mathrm{~s}$ during stretch and circumference measured using ImageJ (v1.44p; National Institutes of Health, Bethesda, MD).

\section{Application of chemicals to afferent endings}

cGMP, inflammatory soup (IS), the endogenous GC-C agonist UGN-A, or negative control peptides uroguanylin-B (UGN-B, an isomer of
UGN-A) and calcitonin were applied to afferent endings in the colorectum as reported previously (Feng and Gebhart, 2011). After establishing a baseline (control) SRF, the receptive ending was isolated $(4 \times 4$ square $\times 10 \mathrm{~mm}$ high tubing), the Krebs' solution removed and replaced by $150 \mu$ l of cGMP or UGN-A ( $5 \mathrm{~min}$ ) or IS or IS plus cGMP ( $3 \mathrm{~min}$ ). The tubing was then removed, re-exposing the ending to Krebs' solution, and a response to the same mechanical stimulus (stretch or probing) acquired immediately after (cGMP and UGN-A) or within 4-6 $\mathrm{min}$ (IS). For each fiber tested with cGMP or UGN-A, SRFs were determined before (control) and after exposure to ascending concentrations (10,30,100, and $300 \mu \mathrm{M}$ for cGMP and 1, 10, 100, and $1000 \mathrm{~nm}$ for UGN-A) with a $15 \mathrm{~min}$ washout between successive applications; $20 \mathrm{~min}$ after exposure to the last concentration tested, an SRF concluded the protocol. In an additional group of eight fibers, the GC-C receptor selectivity of uroguanylin was examined using UGN-A and two negative control peptides (UGN-B and calcitonin; all at $100 \mathrm{~nm}$ ), which were sequentially applied for $5 \mathrm{~min}$ each with a $20 \mathrm{~min}$ washout between successive applications. Only one concentration of IS or IS plus cGMP was tested per fiber; similarly, a final test was conducted following a $20 \mathrm{~min}$ wash period. In some experiments with UGN-A, the colorectum was perfused with Krebs' solution containing probenecid $(100 \mu \mathrm{M})$ to block the transport of cGMP (synthesis stimulated by UGN-A) from epithelial cells.

cGMP was dissolved in Krebs' solution at $15 \mathrm{~mm}$ and prepared in aliquots of $20 \mu \mathrm{l}$. UGN-A was dissolved in $50 \mathrm{~mm}$ sodium phosphate buffer, $\mathrm{pH}$ 6.0, to $600 \mu \mathrm{m}$ and prepared in aliquots of $20 \mu \mathrm{l}$. Probenecid was dissolved in dimethylsulfoxide (DMSO) to $200 \mathrm{~mm}$ and prepared in aliquots of $500 \mu \mathrm{l}$. For evaluation of specificity of action (see Fig. 8), UGN-A, UGN-B, and calcitonin were all dissolved in distilled water to 10 $\mu \mathrm{M}$ and prepared in $10 \mu \mathrm{l}$ aliquots. IS was prepared in aliquots of $20 \mu \mathrm{l}$ by combining bradykinin, serotonin, and histamine dissolved in distilled water with prostaglandin E2 dissolved in DMSO, resulting in $250 \mathrm{~mm}$ concentration for each mediator. All aliquots were frozen, stored at $-20^{\circ} \mathrm{C}$, and diluted on the day of an experiment to final concentrations in freshly oxygenated Krebs' solution (cGMP, UGN-A, UGN-B, calcitonin, and probenecid) or acidic, $\mathrm{pH}$ 6.0, Krebs' solution (10 $\mu \mathrm{M}$ for all mediators of IS) (Feng and Gebhart, 2011). cGMP (300 $\mu \mathrm{M}$ or $30 \mathrm{~mm}$ ) was added to some aliquots of IS before dilution to achieve a final concentration of 10 or $300 \mu \mathrm{M}$ for cGMP and all mediators. The pH of IS and acidic Krebs' solution was adjusted to 6.0 by HCl. UGN-A, UGN-B, and calcitonin were gifts from Ironwood Pharmaceuticals; all other chemicals were purchased from Sigma-Aldrich.

\section{Colorectal hypersensitivity}

As described previously (Feng et al., 2012c), mice were anesthetized (2\% isoflurane; Hospira), the skin incised to expose the right abdominal musculature, and the bare ends of two lengths of Teflon-coated wire (Cooner Wire) inserted into the muscle and secured with 5-0 VICRYL sutures (Ethicon); the other ends were tunneled subcutaneously and externalized through a small skin incision at the nape of the neck. On the day of baseline testing ( $7 \mathrm{~d}$ after surgery), mice were briefly sedated with isoflurane and a lubricated polyethylene balloon $(1.5 \mathrm{~cm}$ long $\times 0.9 \mathrm{~cm}$ diameter) inserted transanally into the colorectum $0.5-1 \mathrm{~cm}$ from the anal verge and secured to the tail with tape. Mice were placed in a plastic cylinder inside a sound-attenuating dark chamber and allowed to recover from isoflurane ( $30 \mathrm{~min}$ ) before testing.

Electromyographic (EMG) activity was recorded continuously for $10 \mathrm{~s}$ before (resting) and $10 \mathrm{~s}$ during phasic colorectal distension (CRD; 15 $\mathrm{mmHg}, 30 \mathrm{mmHg}, 45 \mathrm{mmHg}$, or $60 \mathrm{mmHg}$ ). Each distension pressure was tested three times with 4 min between distensions. After establishing baseline responses to CRD on Day 0, mice received either zymosan (0.1 $\mathrm{ml}$ at $30 \mathrm{mg} / \mathrm{ml}$ dissolved in saline; Sigma-Aldrich) or saline $(0.1 \mathrm{ml})$ intracolonically for 3 consecutive days (Days 0 , 1, and 2); visceromotor responses were assessed by CRD on Days 3, 6, 10, 17, and 24 .

\section{GC-C gene expression by reverse transcription quantitative- $P C R$} and in situ hybridization

Reverse transcription quantitative-PCR. Total RNA from mouse colon was extracted using Trizol (Life Technologies), purified with RNeasy Mini Kit (Qiagen) and used to synthesize cDNAs, $500 \mathrm{ng}$ of which was 
used for detection of GC-C by TaqMan probes for mouse-specific GC-C and GAPDH as control (Life Technologies) (Livak and Schmittgen, 2001).

In situ hybridization. Colorectal tissue was frozen in isopentane to $-35^{\circ} \mathrm{C}$, cryosectioned $(6-10 \mu \mathrm{m})$, mounted on gelatin-coated or Fisher brand SuperFrost Plus slides (Fisher Scientific), and stored at $-80^{\circ} \mathrm{C}$. Before in situ hybridization (ISH), sections were fixed in $4 \%$ formaldehyde (paraformaldehyde; Sigma-Aldrich) in PBS, treated with triethanolamine/acetic anhydride, washed, and dehydrated through graded ethanols (30-100\%). The sequences of GC-C (Gucy2c Mus musculus; PrimerQuest) primers code a fragment of $622 \mathrm{bp}$ within exons 7 and 11 of the transcripts NM 001127318.1 and NM 145067.3. cRNA probes were validated in vitro using SP6 and T7 RNA polymerases. Following validation, antisense and sense probes were synthesized in vitro (Ambion) and radiolabeled with ${ }^{35} \mathrm{~S}$-UTP $(>1000 \mathrm{Ci} / \mathrm{mmol}$; PerkinElmer).

Forward primer: TTTGAGGAGAACACCACAGCTCCT and reverse primer: TGATGTGGTTGGTCTCGTTGGTCT. Sequence is recognized by T7 RNA polymerase: 5'-GCGCTATAATACGACTCACTATAGGGAG A...- $3^{\prime}$. Sequence is recognized by SP6 RNA polymerase: SP6 = 5'-GCATTAATTTAGGTGACACTATAGAAGCG...3'.

Sections were hybridized overnight at $55^{\circ} \mathrm{C}$ in (mM): $300 \mathrm{NaCl}, 20$ Tris- $\mathrm{HCl}, \mathrm{pH} 7.4,5$ EDTA, $10 \mathrm{NaH}_{2} \mathrm{PO}_{4}, 50 \%$ deionized formamide, $10 \%$ dextran sulfate, $1 \times$ Denhardt's, $50 \mu \mathrm{g} / \mathrm{ml}$ total yeast RNA, and $50-80,000 \mathrm{cpm} / \mu \mathrm{l}$ radiolabeled cRNA probe. Tissue sections were washed at $65^{\circ} \mathrm{C}$ in $50 \%$ formamide, $2 \times$ SSC, $10 \mathrm{~mm}$ dithiothreitol and PBS before treatment with $20 \mu \mathrm{g} / \mathrm{ml}$ RNase A at $37^{\circ} \mathrm{C}$ for $30 \mathrm{~min}$, and then washed in $2 \times$ SSC and $0.1 \times$ SSC for $10 \mathrm{~min}$ at $37^{\circ} \mathrm{C}$. The slides were dehydrated and exposed to Kodak BioMaxMR x-ray film for $5 \mathrm{~d}$ followed by dipping in Kodak NTB nuclear track emulsion and exposure in lighttight desiccant boxes at $4^{\circ} \mathrm{C}$ for $14 \mathrm{~d}$. Photographic development was performed in Kodak D-19 and fixed in 35\% sodium thiosulfate solution. Sections were counterstained with cresyl violet and analyzed using bright-field and dark-field microscopy. Sense (control) riboprobes established the level of background signal.

\section{In vitro assay of cGMP accumulation and release in cultured T84 cells}

The human colon carcinoma epithelial cell line T84 was obtained from ATCC and cultured in T-150 flasks to $60-70 \%$ confluency. Monolayers were lifted with trypsin and used to seed 96-well tissue culture plates at a cell density of $2.0 \times 105$ cells/well, which were grown overnight in a $5 \%$ carbon dioxide environment with 2 mM DMEM/F-12 50/50 nutrient mixture supplemented with $5 \%$ fetal bovine serum and L-glutamine (Mediatech). After overnight incubation, cells were washed twice with $0.2 \mathrm{ml}$ of DMEM (Mediatech) without added supplements. To inhibit any phosphodiesterase activity, cells were pre-incubated with $0.180 \mathrm{ml}$ of 1 mM 3-isobutyl-1-methylxanthine (IBMX; Sigma) in DMEM for $10 \mathrm{~min}$ at $37^{\circ} \mathrm{C}$. To inhibit efflux of cGMP, cells were pre-incubated with DMEM containing $0.1 \mathrm{~mm}, 0.5 \mathrm{~mm}$, or $2 \mathrm{~mm} p$-(Dipropylsulfamoyl)benzoic acid (probenecid; Sigma). Standard curves of human UGN-A (Peptides International), human UGN-B (Peptides International), or salmon calcitonin (American Peptide) ranging from 0.1 to 10,000 $\mathrm{nm}$ (final concentration) were prepared for each test article using a Hamilton Microlab Robot (Model STARlet). The GC-C activity assay to measure intracellular changes in cGMP was conducted by incubating $0.02 \mathrm{ml}$ of each standard with $0.180 \mathrm{ml}$ of $1 \mathrm{mM}$ IBMX in DMEM in a 96-well plate for 30 $\min$ at $37^{\circ} \mathrm{C}$. After the incubation, the supernatants were removed and the cells were lysed with cold $0.1 \mathrm{M} \mathrm{HCl}$ for $30 \mathrm{~min}$ on ice. A volume of 175 $\mu \mathrm{l} /$ well of each lysate was transferred to new 96-well plates (Waters) and centrifuged at $1000 \times g$ for $10 \mathrm{~min}$ to remove any cell debris. The resulting supernatants were transferred in $90 \mu \mathrm{l}$ aliquots to new 96-well plates and neutralized to $\mathrm{pH} 7$ with $90 \mu \mathrm{l}$ of $1 \mathrm{~m}$ ammonium acetate. The centrifuged and neutralized T84 cell lysates were analyzed using liquid chromatography with tandem mass spectrometry detection (LC/MS/ MS). To measure efflux of cGMP, T84 cells were pre-incubated with probenecid and stimulated with $1 \mu \mathrm{M}$ human UGN-A. After the $30 \mathrm{~min}$ incubation time, the supernatants were removed and analyzed by LC/ MS/MS. cGMP (Sigma) was used to prepare a standard curve in $0.1 \mathrm{M}$ $\mathrm{HCl}$ (for lysate samples) or in DMEM (for supernatant samples). cGMP standards made in $0.1 \mathrm{M} \mathrm{HCl}$ were prepared as a $2 \times$ concentrate and then neutralized with an equal volume of ammonium acetate. Both standard curves had final concentrations of 1-1024 nM.

\section{Data recording and analysis}

EMG activity was amplified, filtered, rectified, and quantified using Spike 2 software (Cambridge Electronic Design [CED]) and recorded on a PC. SRFs were quantified as the total area of EMG activity during balloon inflation (10 s) minus resting activity recorded in the $10 \mathrm{~s}$ period immediately preceding colorectal distension.

Action potentials (APs) were recorded extracellularly using a lownoise AC differential amplifier. Activity was monitored on-line, filtered $(0.3-10 \mathrm{kHz})$, amplified $(\times 10,000)$, digitized at $20 \mathrm{kHz}$ using a 1401 interface (CED), and stored on a PC. APs were discriminated off-line using Spike 2 software. To avoid erroneous discrimination, no more than two clearly discriminable units in any record were studied. The stretch response threshold was defined as the force that evoked the first AP during ramped stretch. Afferents included low- and high-threshold (HT; $>68 \mathrm{mN}$ ) subgroups as previously described (Feng et al., 2010). For low-threshold (LT) stretch-sensitive afferents, SRFs are generally presented as bins of evoked APs $(0-57,57-113$, and $113-170 \mathrm{mN})$ whereas responses of HT stretch-sensitive afferents are presented as total number of APs during ramped stretch. To facilitate comparison, responses of some LT stretch-sensitive afferents are also presented as total number of APs during ramped stretch; statistical analyses of these data used total number of APs during stimulation. For serosal and mucosal afferents, evoked APs during stimulation were quantified and plotted as SRFs. SRFs were normalized to the respective maximum binned spike number $(100 \%)$ in control tests. Data are presented throughout as mean \pm SEM. One-way and two-way ANOVA or repeated measures was performed as appropriate using SigmaPlot v9.0 (Systat software). Bonferroni post hoc multiple comparisons were performed when $F$ values for main effects were significant. Differences were considered significant when ${ }^{\star} p<0.05$.

\section{Results}

\section{Effect of cGMP on stretch-sensitive afferents}

Responses of 33 muscular and $36 \mathrm{M} / \mathrm{M}$ afferents to stretch were studied; representative recordings are shown in Figures $1 A$ and $2 A$. Local application of cGMP had no effect on colorectal compliance (Fig. 1B). Consistent with our previous study (Feng et al., 2010) showing that $\sim 14 \%$ of stretch-sensitive colorectal afferents have high thresholds for response ( $>68 \mathrm{mN}, \sim 20 \mathrm{mmHg}$ of colorectal distension) to stretch, histograms of response thresholds from muscular (Fig. 1C) and M/M (Fig. 1D) afferents revealed low-threshold $(<68 \mathrm{mN})$ and $\mathrm{HT}(>68 \mathrm{mN})$ subgroups. cGMP attenuated responses of LT muscular afferents to stretch only at greater concentrations of 100 and $300 \mu \mathrm{M}$ (Fig. $1 E$; overall $F_{(5,60)}=$ 4.6, $p<0.001$; post hoc comparisons, $p<0.001$ for $100 \mu \mathrm{M}, p<0.05$ for $300 \mu \mathrm{M})$; responses to stretch recovered after washout $(p=0.323$ vs control). Responses of LT M/M fibers to stretch were significantly reduced by all four cGMP concentrations tested (Fig. 1F; overall $F_{(5,65)}=13.6, p<0.001$; post hoc comparisons, $p<0.001$ vs control for all cGMP concentrations); the effects of cGMP completely washed out ( $p=1$ vs control). Because cGMP did not exhibit clear concentration-dependent effects, a lower concentration of cGMP (3 $\mu \mathrm{M}$ ) was tested on $8 \mathrm{LT}$ muscular and 9 LT M/M afferents (Fig. $1 G, H$; data summarized for all concentrations of cGMP tested). Responses to stretch of muscular afferents were unaffected except at $100 \mu \mathrm{M}$ cGMP (Fig. $1 G$; overall $F_{(6,95)}=3.4, p<0.05$; post hoc comparisons, $p=0.001$ for $100 \mu \mathrm{M}$ vs control) whereas responses of $\mathrm{M} / \mathrm{M}$ afferents were significantly reduced (Fig. $1 H$; overall $F_{(6,104)}=$ $11.3, p<0.001$; post hoc comparisons, $p<0.05$ vs control for all cGMP concentrations).

Responses of HT muscular and M/M afferents to stretch were unaffected by cGMP except at the lowest concentration tested (10 $\mu \mathrm{M})$. Limited by the relatively low proportion of HT afferents 
A

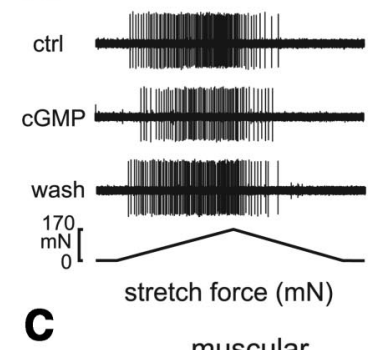

muscular

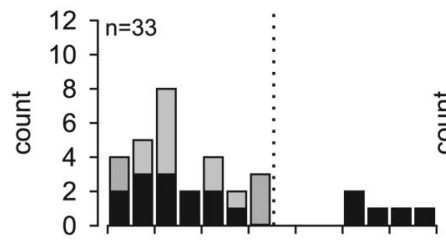

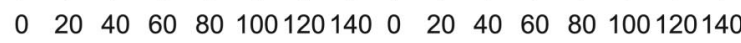

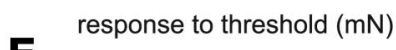

$$
\text { E }
$$

LT muscular
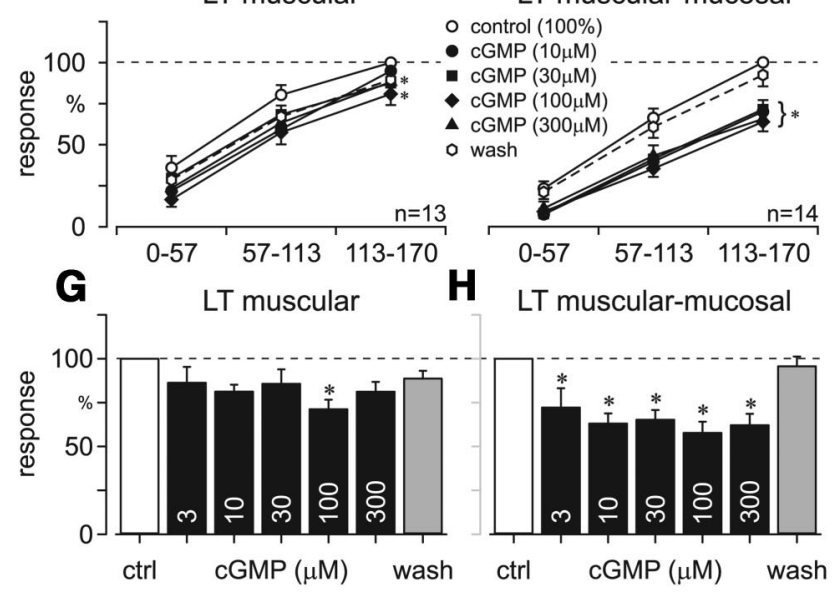

F LT muscular-mucosal

○ control $(100 \%)$

cGMP $(10 \mu \mathrm{M})$

cGMP $(10 \mu \mathrm{M})$ - - - - - - - - - -

- cGMP $(30 \mu \mathrm{M})$

$\operatorname{cGMP}(300 \mu \mathrm{M}), 0$

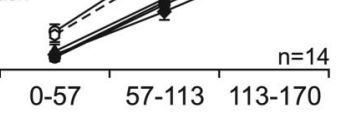

$\mathbf{H}$

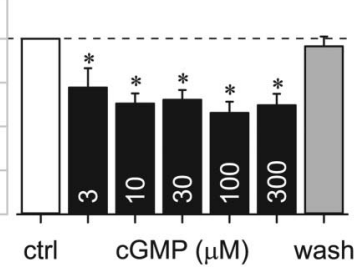

Figure 1. Effect of CGMP on stretch-sensitive muscular and M/M afferents. $A$, Representative responses to ramped circumferential stretch $(0-170 \mathrm{mN}$ at $5 \mathrm{mN} / \mathrm{s})$ of an $\mathrm{M} / \mathrm{M}$ afferent before (ctrl), after exposure to CGMP $(10 \mu \mathrm{M})$, and after washout. $\boldsymbol{B}$, Colorectal compliance, measured as the circumference across the receptive field, was unaffected by GGMP. C, Histograms of response thresholds for muscular and M/M afferents (D). Both fiber classes included HT ( $>68$ $\mathrm{mN})$ and $\mathrm{LT}(<68 \mathrm{mN})$ subgroups as indicated by the broken line at $68 \mathrm{mN}$. Because $L T$ afferents are more commonly encountered, CGMP was tested only on $13 \mathrm{LT}$ muscular and $14 \mathrm{LT}$ M/M afferents that were first encountered. $\boldsymbol{E}$, Responses of $\mathrm{LT}$ muscular afferents and of $L T M / M$ afferents $(\boldsymbol{F})$ were significantly attenuated by $\mathrm{CGMP}(10-300 \mu \mathrm{M})$. A lower concentration of CGMP was also tested and all data are summarized (total number of APs during ramped stretch normalized to control $=100 \%$ ) in $\boldsymbol{G}$ for muscular and in $\boldsymbol{H}$ for $\mathbf{M} / \mathbf{M}$ afferents. ${ }^{*}$, traces significantly different from control $(p<0.05)$; see Results for details.

$(\sim 14 \%)$ in addition to the low-yield nature of single-fiber recordings, the effect of cGMP was tested on fewer HT afferents (five muscular and seven M/M) than LT muscular and M/M afferents, thus practically reducing the power normally associated with a repeated-measures ANOVA. Accordingly, protected paired $t$ tests were used to compare each test concentration with control. Representative recordings are shown in Figure $2 A$ and summarized results in Figure $2 B$ and $C$.

Effect of cGMP on serosal and mucosal afferents

Representative recordings of a serosal afferent to computercontrolled probing are shown in Figure $3 A$. cGMP did not affect responses of either serosal (Fig. $3 B$; overall $F_{(5,30)}=0.97, p=$

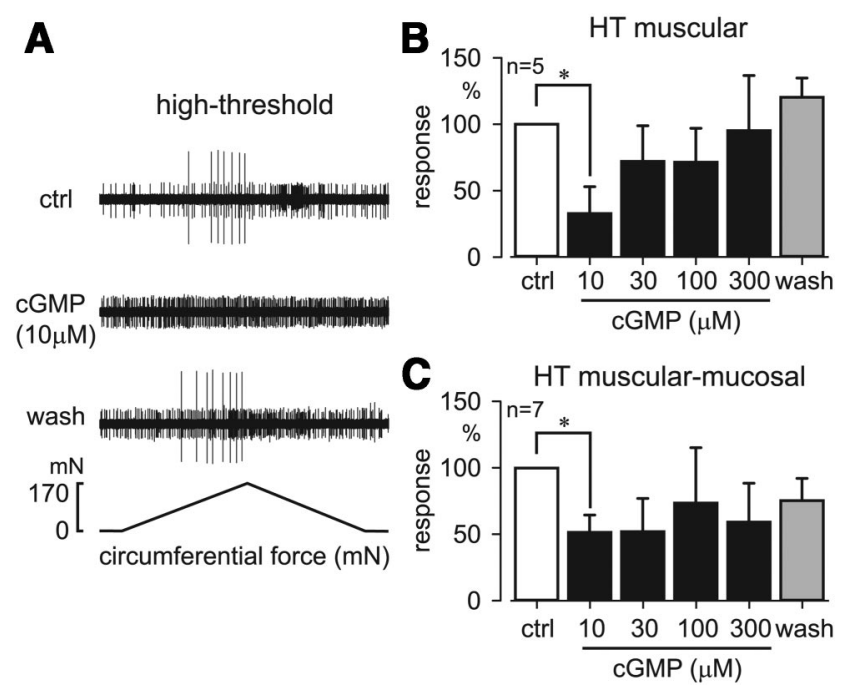

Figure 2. Effect of cGMP on HT stretch-sensitive colorectal afferents. $\boldsymbol{A}$, Representative recordings of an HT muscular afferent to ramped stretch before (ctrl), after exposure to cGMP (10 $\mu \mathrm{M})$, and after washout. Responses to stretch were quantified as total number of APs during ramped stretch, normalized to control $=100 \%$, and are summarized in $\boldsymbol{B}$ for muscular and $\boldsymbol{C}$ for $\mathrm{M} / \mathrm{M}$ afferents $\left({ }^{*} p<0.05\right)$.

0.45 ) or mucosal afferent endings (Fig. $3 C$; overall $F_{(5,30)}=0.18$, $p=0.97)$ at any concentration tested.

\section{Effect of cGMP on acute sensitization of stretch-sensitive afferents}

Application of IS significantly increased (sensitized) responses to stretch of both muscular (Fig. $4 A ; F_{(2,22)}=9.5$, post hoc comparison, $p<0.01$ ) and M/M (Fig. $4 B ; F_{(2,28)}=6.6$, post hoc comparison, $p<0.02)$ afferents, which completely reversed after IS washout ( $\sim 20 \mathrm{~min})$. We assessed the effect of cGMP on acute sensitization produced by IS by combining IS with cGMP. Sensitization of muscular afferents by IS was unaffected by a low concentration of cGMP ( $10 \mu \mathrm{M}$; Fig. $4 C ; F_{(2,22)}=4.6, p<0.03$ vs control), but was attenuated by a greater concentration of cGMP and did not differ from control or wash $\left(300 \mu \mathrm{M}\right.$; Fig. $4 E ; F_{(2,22)}=$ $3.3, p>0.05)$. As summarized in Figure $4 F$, responses of muscular afferents to stretch in the presence of IS alone and IS $+10 \mu \mathrm{M}$ cGMP significantly differed from control and wash (overall $F_{(4,103)}=10.8, p<0.001$; post hoc comparisons, $p<0.002$ for IS and IS $+10 \mu \mathrm{M}$ cGMP vs control and wash) whereas responses in the presence of IS $+300 \mu \mathrm{M}$ cGMP did not differ from either control or wash $(p>0.9)$. Sensitization of $\mathrm{M} / \mathrm{M}$ afferents by IS was fully prevented by $10 \mu \mathrm{M}$ cGMP (Fig. $\left.4 D ; F_{(2,28)}=1.7\right) ; \mathrm{M} / \mathrm{M}$ responses to stretch in the presence of cGMP $(10 \mu \mathrm{M})$ did not differ from either control or wash (Fig. $4 F$; overall $F_{(3,86)}=8, p<$ 0.001 , post hoc comparison, $p>0.9$ for IS $+10 \mu \mathrm{M}$ cGMP).

Effect of cGMP on persistently sensitized colorectal afferents The ability of cGMP to attenuate persistent, established sensitization was assessed in a model of colorectal hypersensitivity induced by intracolonic instillation of zymosan. Saline-treated mice displayed no changes in visceromotor responses to colorectal distension at any time after intracolonic treatment (Fig. 5A; $\left.F_{(5,95)}=0.22, p=0.95\right)$, whereas visceromotor responses in zymosan-treated mice were significantly enhanced (sensitized) (Fig. $5 B$; overall $F_{(5,90)}=3.4, p=0.007$ ). After the last CRD tests (Day 24), the colorectum and pelvic nerve were harvested for in vitro single-fiber recordings from both saline- and zymosan- 


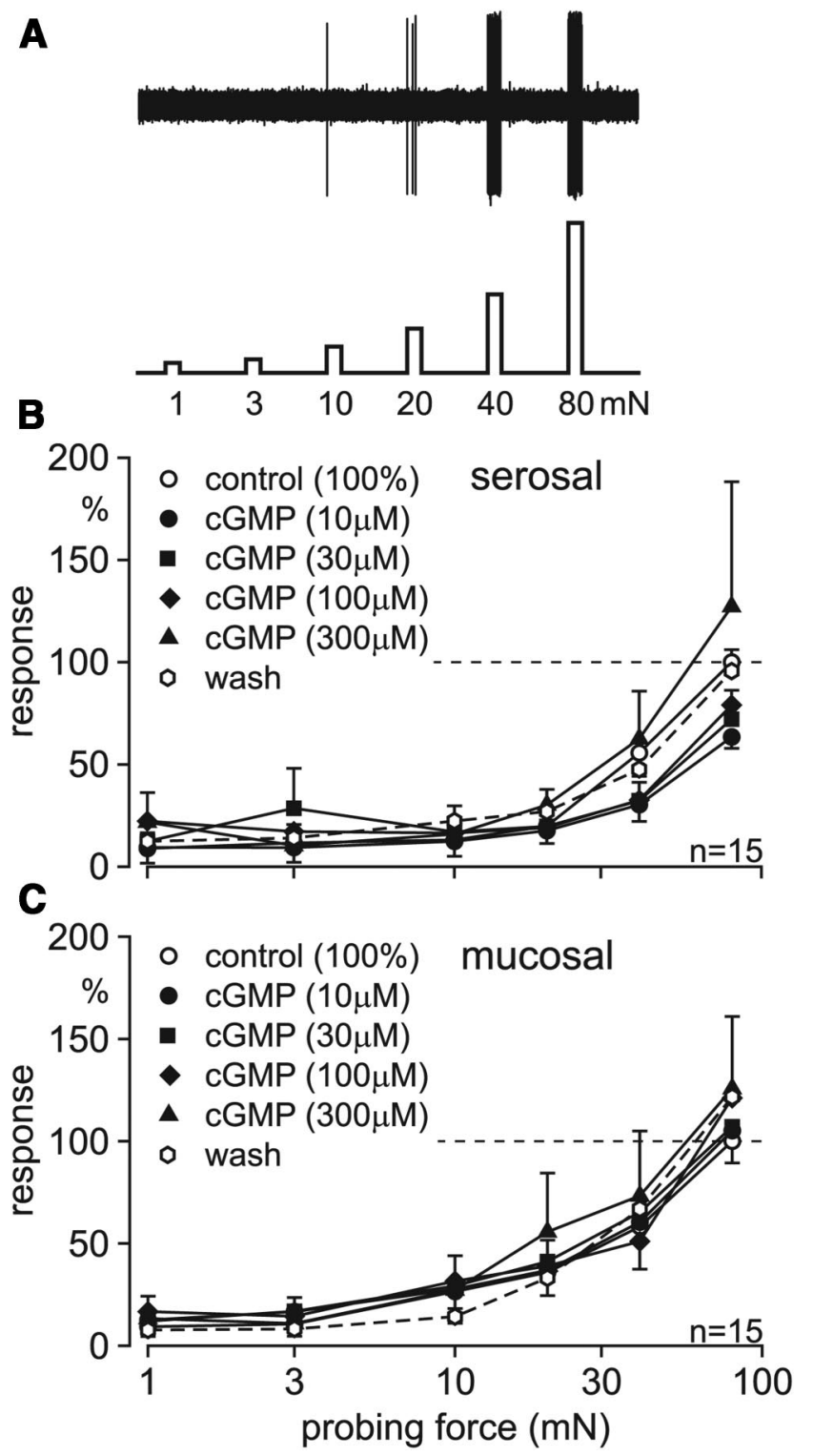

Figure 3. Effect of cGMP on serosal and mucosal afferents. Afferents were tested by perpendicular probing of their receptive fields using a computer-controlled force actuator $(1-80 \mathrm{mN}$, $5 \mathrm{~s}$ steps). $\boldsymbol{A}$, Representative recording of a serosal afferent. Responses of serosal $(\boldsymbol{B})$ and mucosal ( $C$ ) afferents were not affected by any concentration of cGMP tested.

treated mice. Consistent with previous work (Feng et al., 2012c), responses of muscular afferents to stretch were similar between zymosan- and saline-treated mice (Fig. $5 C ; F_{(1,108)}=0.65, p=$ 0.42 ), whereas $M / M$ afferents from zymosan-treated mice exhibited sensitized responses to stretch (Fig. $5 D ; F_{(1,87)}=19, p<$ 0.001 vs saline-treated counterparts).

Consistent with results in naïve mice (Fig. $1 E$ ), cGMP attenuated responses of LT muscular afferents to stretch in salinetreated mice only at greater concentrations (Fig. 6A; overall $F_{(5,65)}=5.79, p<0.001$; post hoc comparisons, $p<0.05$ for 100 and $300 \mu \mathrm{M}$ ) and had no effect in zymosan-treated mice (Fig. $6 C$; $\left.F_{(5,70)}=1.7, p=0.15\right)$. Also consistent with findings in naïve mice (Fig. $1 F$ ), responses of LT M/M afferents to stretch were significantly reduced by all cGMP concentrations tested in both saline-treated (Fig. $6 B$; overall $F_{(5,55)}=5.5, p<0.001$; post hoc comparisons, $p<0.01$ for all concentrations) and zymosantreated groups (Fig. $6 D$; overall $F_{(5,70)}=7.9, p<0.001$; post hoc
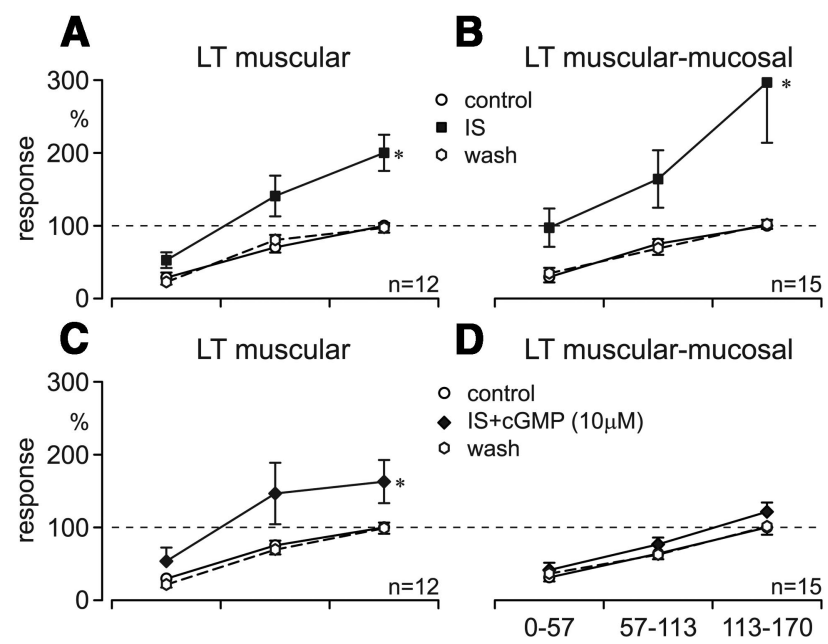

D LT muscular-mucosal

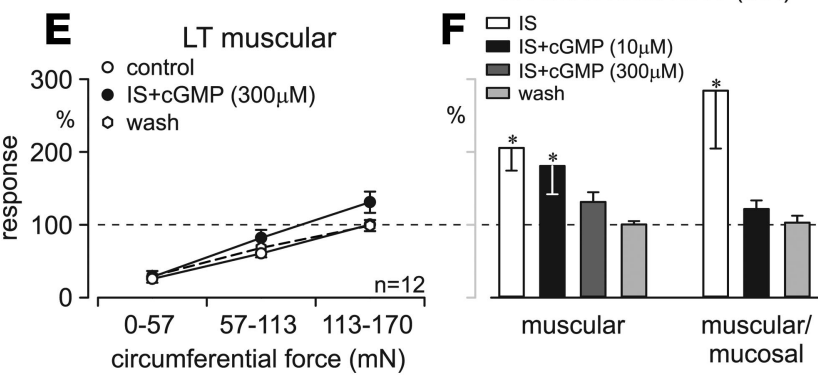

Figure 4. CGMP modulates acute sensitization of LT stretch-sensitive afferents. Both LT muscular $(\boldsymbol{A})$ and $\mathrm{M} / \mathrm{M}(\boldsymbol{B})$ afferent responses to stretch were sensitized by exposure (3 $\mathrm{min}$ ) to IS. A $10 \mu \mathrm{m}$ concentration of $\mathrm{GGMP}$ did not prevent the sensitization of muscular afferents $(C)$ but a greater concentration $(300 \mu \mathrm{M})$ did $(\boldsymbol{E})$. Sensitization of $\mathrm{M} / \mathrm{M}$ afferents was completely abolished by $10 \mu \mathrm{M} \mathrm{CGMP}(\boldsymbol{D})$. To facilitate comparisons, data in $\boldsymbol{A}-\boldsymbol{E}$ are summarized and presented in $\boldsymbol{F}$ as total APs during ramped stretch normalized to control $=100 \%$. The vertical axis in all parts is response (\% control). ${ }^{*} p<0.05$; see Results for details.

comparisons, $p<0.001$ for all concentrations). Figure $6, E$ and $F$, summarizes responses of LT muscular $(E)$ and $\mathrm{M} / \mathrm{M}(F)$ afferents to stretch in the absence (pre-cGMP) and presence of cGMP, respectively. Responses of muscular afferents did not differ between saline- and zymosan-treated groups before versus after cGMP at either $10 \mu \mathrm{M}$ or $300 \mu \mathrm{M}$ cGMP (Fig. $6 E ; F_{(5,81)}=0.47$, $p=0.8$ ). In contrast, pre-cGMP responses of $\mathrm{M} / \mathrm{M}$ afferents from zymosan-treated mice were sensitized relative to their salinetreated counterparts (Fig. $6 F$; overall $F_{(3,50)}=6.1, p=0.01$; post hoc comparison, $p=0.02)$. cGMP $(10 \mu \mathrm{M})$ significantly attenuated responses of $\mathrm{M} / \mathrm{M}$ afferents from both saline- (paired $t$ test, $p<0.002)$ and zymosan-treated mice $(p<0.03)$ and fully reversed zymosan-induced persistent sensitization; responses to stretch after cGMP in zymosan-treated mice were comparable to baseline responses in saline-treated mice (post hoc comparison, $p>0.26$ ).

Responses of serosal afferents to ascending steps ( $5 \mathrm{~s}$ ) of probing force were tested on 15 afferents from zymosan-treated mice and 15 afferents from saline-treated mice (data not shown). Baseline responses of serosal afferents were not different between saline- and zymosan-treated groups $\left(F_{(1,168)}=0.39, p=0.53\right)$. Similar to results in naïve mice (Fig. $3 B$ ), responses of serosal afferents to probing were unaffected by cGMP in either salinetreated $\left(F_{(5,70)}=0.6, p=0.69\right)$ or zymosan-treated groups $\left(F_{(5,70)}=0.25, p=0.94\right)$. 
A
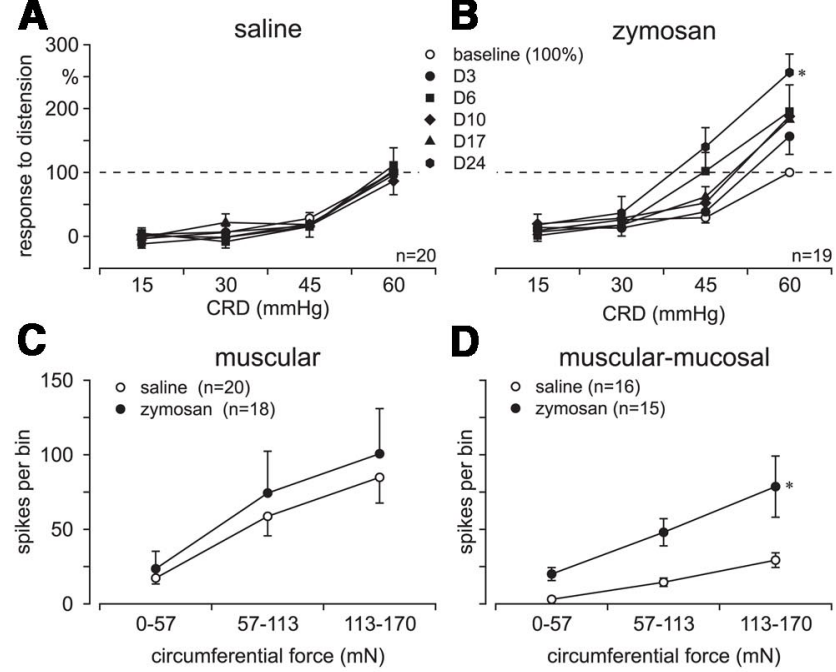

D muscular-mucosal

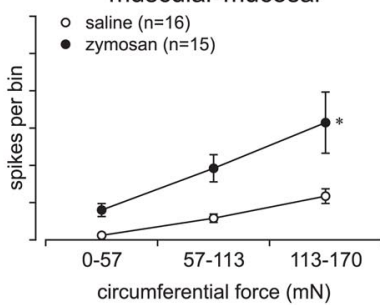

E

saline (antisense)

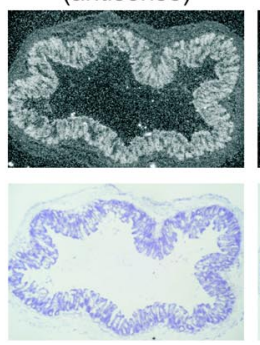

zymosan
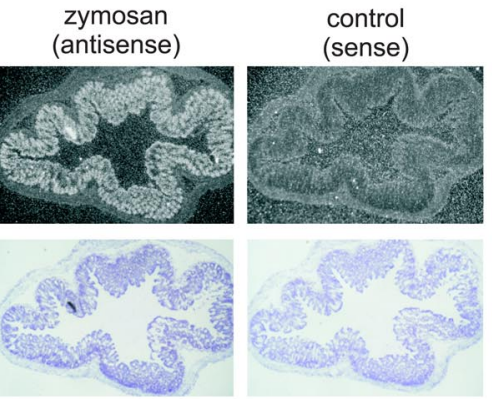

Figure 5. Intracolonic zymosan produces colorectal hypersensitivity and sensitizes afferents. $\boldsymbol{A}$, Intracolonic saline did not affect visceromotor responses to CRD whereas $(\boldsymbol{B})$ intracoIonic zymosan significantly enhanced visceromotor responses, after which on Day 24 (D24) colorectums were harvested for single-fiber recording. C, Muscular afferent responses to stretch did not differ between saline- and zymosan-treated mice whereas $M / M$ afferents $(\boldsymbol{D})$ were sensitized. ${ }^{*} p<0.05$; see text for details. $E$, Hybridization with GC-C antisense probe revealed the presence of $\mathrm{GC}-\mathrm{C}$ mRNA in the mucosal layer of both saline- and zymosan-treated colons; sense probe detected no signal. Corresponding images below are adjacent cresyl violet stained colonic sections.

\section{Activation of GC-C modulates responses of stretch-sensitive afferents through synthesis and extracellular transport of cGMP}

The foregoing establishes that cGMP, the primary downstream effector of GC-C activation, decreases baseline responses and prevents sensitization of stretch-sensitive colorectal afferents. We next tested the effect of UGN-A, an endogenous GCCA, on responses to stretch of $14 \mathrm{LT}$ muscular and $15 \mathrm{LT} \mathrm{M} / \mathrm{M}$ afferents. Similar to cGMP, low concentrations of UGN-A ( 1 and $10 \mathrm{nM}$ ) had no significant effect on responses of LT muscular afferents (Fig. $7 A$; overall $F_{(5,65)}=5.1, p<0.001$; post hoc comparison vs control, $p>0.12$ ) whereas responses were significantly attenuated at greater concentrations ( $p o s t$ hoc comparisons, $p=0.035$ for $100 \mathrm{nM}, p=0.001$ for $1000 \mathrm{nM})$. Consistent with the effects of cGMP, responses to stretch of LT M/M afferents were significantly attenuated by all four concentrations of UGN-A (Fig. 7B; overall $F_{(5,70)}=19.1, p<0.001$; post hoc comparisons, $p<0.001$ for all concentrations). Additional tests were conducted on 8 muscular and $10 \mathrm{M} / \mathrm{M}$ afferents at a lower $0.1 \mathrm{nM}$ concentration of UGN-A (Figs. 7C,D; data summarized for all concentrations of UGN-A tested). Responses of muscular afferents were unaffected except at 1000 nм UGN-A (Fig. $7 C$; overall $F_{(6,101)}=4.1, p<$ 0.001; post hoc comparisons, $p<0.01$ for $1000 \mathrm{~nm}$ vs control) whereas responses of $\mathrm{M} / \mathrm{M}$ afferents were significantly attenuated
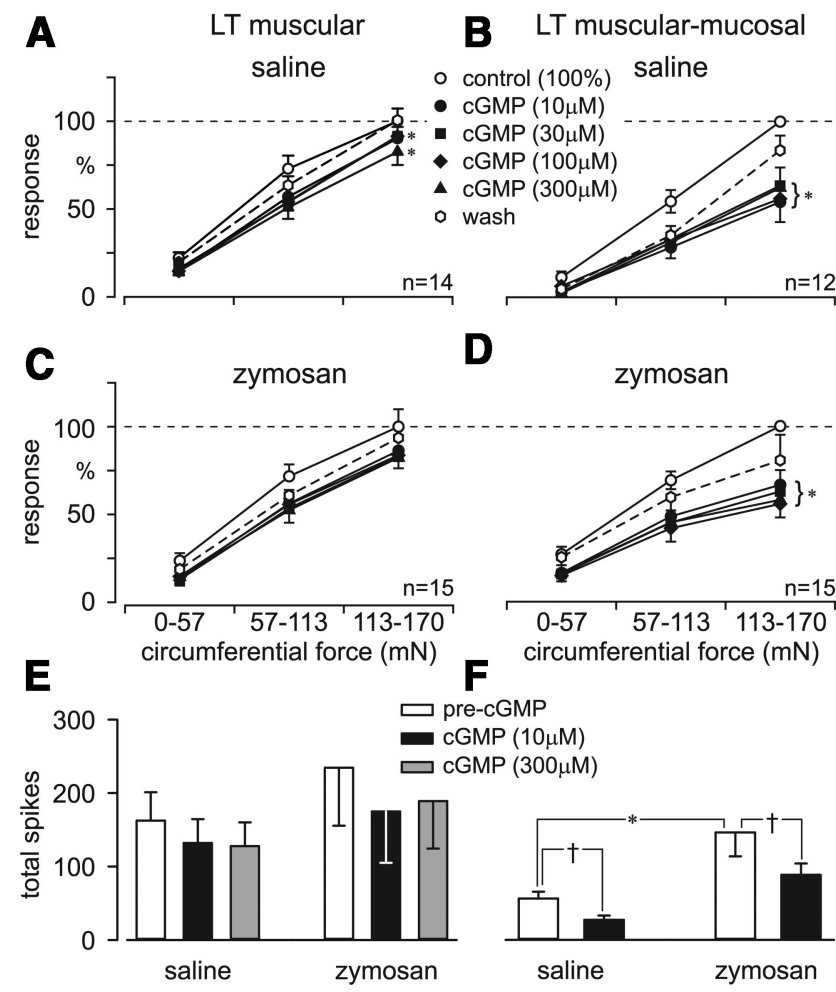

Figure 6. Effect of CGMP on stretch-sensitive afferents from mice with persistent colorectal hypersensitivity. CGMP attenuated responses of LT muscular afferents to stretch in salinetreated $(\boldsymbol{A})$ but not zymosan-treated groups ( $\boldsymbol{C}$. Responses of M/M afferents to stretch were significantly attenuated by all concentrations of CGMP tested in both saline $(\boldsymbol{B})$ and zymosantreated groups $(\boldsymbol{D})$. Responses of muscular and $\mathrm{M} / \mathrm{M}$ afferents (without normalization) are presented as total APs during ramped stretch in $\boldsymbol{E}$ and $\boldsymbol{F}$, respectively. Responses of muscular afferents to stretch were not different between saline- and zymosan-treated groups before or after $10 \mu \mathrm{M}$ or $300 \mu \mathrm{M} \mathrm{CGMP}$ application. In contrast, responses to stretch were sensitized in zymosan-treated versus saline-treated mice $\left({ }^{*} p<0.05\right)$ and $10 \mu \mathrm{m} \mathrm{CGMP}$ reversed the sensitization of M/M afferents in both saline- and zymosan-treated mice $(t p<0.05)$; responses in zymosan-treated mice after cGMP are comparable to baseline responses from saline-treated control mice.

by all concentrations of UGN-A (Fig. $7 D$; overall $F_{(6,113)}=16$, $p<0.0001$; post hoc comparisons, $p<0.001$ vs control for all UGN-A concentrations except $0.1 \mathrm{nM}$ ). UGN-A had no effect on colorectal compliance (data not shown).

The addition of $100 \mu \mathrm{M}$ probenecid to the Krebs' solution perfusing the colorectum abolished the effects of UGN-A (10 nM) on LT M/M afferents (Fig. 7E; $F_{(2,12)}=0.18, p=0.84$ ). Probenecid did not affect colorectal compliance (Fig. $7 F$ ) nor did it affect basal responses of M/M afferents to stretch. There was no significant difference between the basal (control) responses of $25 \mathrm{M} / \mathrm{M}$ afferents in this study recorded in the presence of Krebs' solution (Fig. 7D, ctrl) and the seven M/M afferents recorded in the presence of Krebs' plus100 $\mu \mathrm{M}$ probenecid (Fig. $7 E$, pro; $F_{(1,90)}=$ $0.17, p=0.7$ ).

To establish that probenecid is efficacious in blocking the synthesis and release of cGMP, we used cultured intestinal T84 cells that express endogenous GC-C. UGN-A increased the cGMP concentration in lysates (intracellular cGMP) of cultured T84 cells $\left(\mathrm{EC}_{50}=526 \pm 120 \mathrm{nM}\right)$ whereas its isomeric control peptide UGN-B and calcitonin were without effect over the same range of concentrations tested (Fig. 8A). Probenecid dose dependently inhibited uroguanylin-stimulated cGMP release into the supernatant of cultured T84 cells, a measure of extracellular cGMP (Fig. $8 B$; overall $F_{(3,12)}=7.2, p<0.01$; post hoc comparisons, $p<$ 


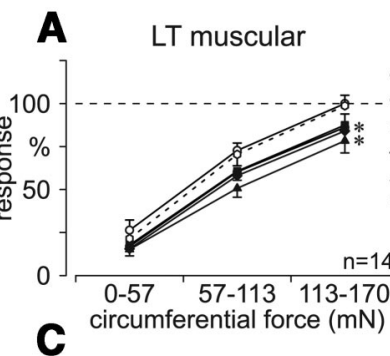

B LT muscular-mucosal - control $(100 \%)$ - UGN-A (1nM)

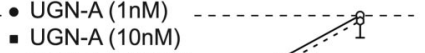
- UGN-A (100nM) UGN-A (100nM)
UGN-A (1000nM)
wash
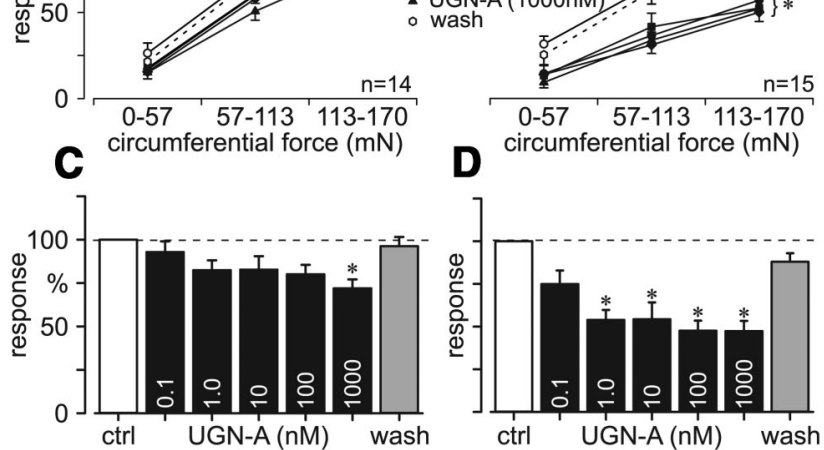

D

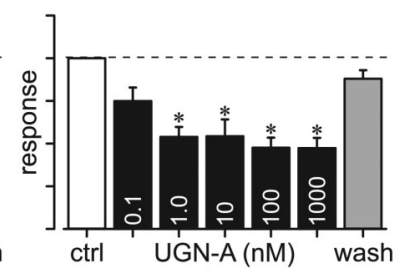

E muscular-mucosal fibers
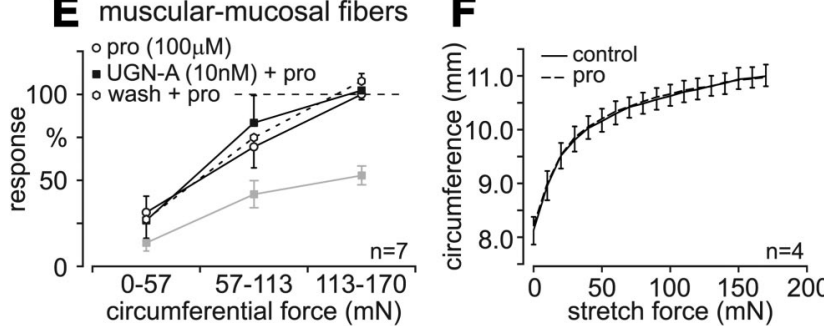

Figure 7. Effect of GC-C activation by UGN-A on LT stretch-sensitive afferents. Similar to CGMP, only greater concentrations of UGN-A reduced responses of muscular afferents to stretch $(\boldsymbol{A})$, whereas UGN-A attenuated responses of $\mathrm{M} / \mathrm{M}$ afferents at all concentrations tested $(\boldsymbol{B})$. A lower concentration of UGN-A $(0.1 \mathrm{~nm})$ was also tested all data are summarized (total number of APs during ramped stretch normalized to control $=100 \%$ ) in ( for muscular and in $\boldsymbol{D}$ for $\mathrm{M} / \mathrm{M}$ afferents. ${ }^{*} p<0.05$; see Results for details. The addition of probenecid (100 $\left.\mu \mathrm{M}\right)$ to the perfused Krebs' solution abolished the inhibitory effect of UGN-A (10 nM) on M/M afferents (E). To facilitate comparisons, the effect of $10 \mathrm{~nm} U$ GN- $A$ on M/M afferents presented in $\boldsymbol{B}$ is reproduced in $\boldsymbol{E}$ in half-tone. Probenecid did not affect colorectal compliance measured by colon circumference during stretch $(\boldsymbol{F})$.

0.01 for $2000 \mu \mathrm{M}$ probenecid vs control). We further established selectivity of effect functionally; responses of $\mathrm{M} / \mathrm{M}$ afferents to stretch were inhibited by UGN-A, but not by UGN-B or calcitonin (Fig. $8 C$; all at $100 \mathrm{nM}$, overall $F_{(4,32)}=3.87, p=0.011$; post hoc comparisons, $p<0.02$ for UGN-A; $p>0.9$ for UGN-B and calcitonin).

\section{GC-C gene expression and in situ hybridization}

GC-C mRNA in the colon was detected by reverse transcription $\mathrm{PCR}$, revealing comparable relative expression in saline-treated $(0.1, n=2)$ and zymosan-treated $(0.14, n=2)$ treated mice. ISH of colonic tissue sections with antisense (but not sense) probes (Fig. $5 E$ ) revealed the presence of GC-C mRNA in the mucosal layer in both saline- and zymosan-treated mice.

\section{Discussion}

Persistent pain and hypersensitivity in IBS is typically difficult to manage. Clinical and preclinical evidence reveals that enhanced afferent input from the periphery is necessary for the development and maintenance of IBS-related pain, including referred somatic hypersensitivity (Verne et al., 2003, 2005; Zhou et al., 2008), reinforcing the importance of afferent input to central sensitization. The present study provides evidence that local activation of GC-C attenuates colorectal afferent input in both naive and sensitized states through synthesis and extracellular transport of cGMP, and thus likely underlies the antihyperalgesic
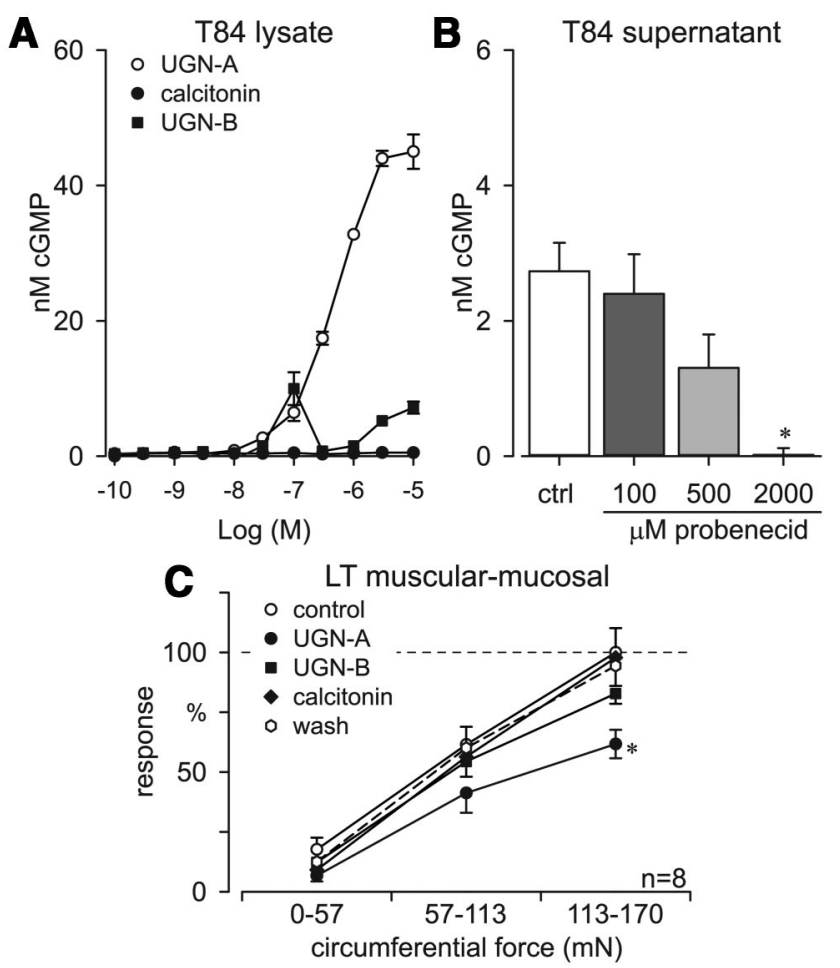

Figure 8. Effect of $\mathrm{GC}-\mathrm{C}$ activation on the synthesis and release of CGMP. UGN-A, but not isomeric UGN-B or calcitonin, dose dependently triggered an increase in CGMP concentration in T84 cell lysates in vitro $(\boldsymbol{A})$. In support, application of UGN-B and calcitonin on eight M/M afferents had no effect on their response to stretch whereas UGN-A significantly attenuated the stretch response (C). Uroguanylin-stimulated release of CGMP in T84 cells as indicated by increased supernatant cGMP concentration was dose dependently inhibited by probenecid $(\boldsymbol{B})$.

mechanism of linaclotide, a GCCA (Busby et al., 2013), in patients with IBS-C (Chey et al., 2012; Rao et al., 2012).

It is well documented that GC-C expression is largely restricted to intestinal epithelial cells; there is no evidence that neuronal elements in the intestine express GC-C (Lucas et al., 2000; Basu et al., 2010). Accordingly, the antihyperalgesic effect of GC-C activation is likely indirect and involves downstream effectors that act on colorectal afferent endings. Recent studies indicate that binding of GCCAs at the apical surface of an intestinal epithelia cell line catalyzes the synthesis of intracellular cGMP (Busby et al., 2010) and promotes its extracellular release from the basolateral membrane (I. Silos-Santiago et al., unpublished observation). In support, local mucosal application of cGMP (3$300 \mu \mathrm{M})$ in the present study significantly reduced responses of LT muscular and M/M afferents to circumferential stretch, although effects of cGMP on LT muscular afferents were apparent only at the greater concentrations tested (100-300 $\mu \mathrm{M})$. This may be accounted for by the likely extension of the sensory endings of $\mathrm{M} / \mathrm{M}$ afferents into the mucosal layer of the colorectum in closer proximity to the luminal surface where cGMP was applied. Dosedependent inhibition of $\mathrm{M} / \mathrm{M}$ afferents by cGMP $(10-300 \mu \mathrm{M})$ or UGN-A (1-1000 nM) was not apparent whereas lesser concentrations of cGMP $(3 \mu \mathrm{M})$ or UGN-A (100 pM) moderately attenuated responses of $\mathrm{M} / \mathrm{M}$ afferents, suggesting that greater concentrations were equally saturating. This observation is consistent with the nanomolar $\mathrm{IC}_{50}$ of UGN-A reported previously in a binding assay (Busby et al., 2010).

In the present study, $17 \%$ of stretch-sensitive afferents $(5 / 33$ muscular, $7 / 36 \mathrm{M} / \mathrm{M}$ ) had high thresholds for response to stretch ( $>68 \mathrm{mN}$, equivalent to a distension pressure of $\sim 20 \mathrm{mmHg}$ ), 
consistent with a previous report (Feng et al., 2010). Interestingly, cGMP reduced responses to stretch of both HT muscular and $\mathrm{M} / \mathrm{M}$ afferents to stretch only at the lowest concentration tested $(10 \mu \mathrm{M})$; greater concentrations of cGMP $(30-300 \mu \mathrm{M})$ had no effect on either fiber class. This observation is consistent with a previous study that examined the effect of linaclotide on rodent responses to colorectal distension, the outcome of which showed reduced antihyperalgesic effects at lower doses and an overall bell-shaped dose-response curve (Eutamene et al., 2010). Collectively, LT and HT stretch-sensitive afferents appear to have different sensitivities to cGMP (as judged by their dose-response curves in the presence of cGMP); $10 \mu \mathrm{M}$ cGMP appears to be the optimal concentration to produce a saturating inhibition of LT-M/M afferents and an attenuated response of HT stretchsensitive afferents.

Serosal afferents do not respond to either colorectal stretch or fine mucosal stroking and only reliably respond to mechanical probing of their receptive fields (Feng and Gebhart, 2011). Unlike previous studies in which responses of serosal afferents were quantified by probing of the receptive field with hand-held von Frey-like monofilaments (Brierley et al., 2004; Jones et al., 2005, 2007; Hughes et al., 2009), the current study used a servocontrolled force actuator to precisely and reproducibly deliver probing forces to the receptive field using a thick $(\phi 1 \mathrm{~mm})$, blunt monofilament. We observed no significant effect of cGMP on responses of serosal afferents to probing. This could be interpreted as the absence of a molecular target(s) for cGMP on serosal afferents or, alternatively, as limited/no access to serosal endings by cGMP applied to the luminal surface of the colorectum. Morphological information about serosal endings in the colorectum is limited, with speculation including that they are located in the serosa (because of their high mechanical response thresholds; Blackshaw et al., 2007) or the submucosa close to the colon vasculature (Zagorodnyuk et al., 2010). Both interpretations suggest a lack of proximity of serosal endings to the mucosa where cGMP is released endogenously upon GC-C activation. SRFs of mucosal afferents were quantified here in the same fashion as serosal afferents, and they too were unaffected by cGMP. This agrees with previous studies showing that mechanical responses of mucosal afferents were generally unaffected by chemical mediators (for review, see Feng et al., 2012b).

cGMP was shown in the present study to prevent acute sensitization of $\mathrm{M} / \mathrm{M}$ afferents by inflammatory soup applied to their receptive endings. Interestingly, cGMP prevented sensitization of muscular afferents only at a greater concentration $(300 \mu \mathrm{M})$, corresponding well to the differential responses of these afferent classes to cGMP (Fig. $1 E, F$ ). Importantly, cGMP reversed persistent sensitization of $\mathrm{M} / \mathrm{M}$ afferents recorded in colorectums from mice established as behaviorally hypersensitive to colorectal distension. Given that afferent sensitization (i.e., enhanced input from normal, physiologic colorectal stimuli) is important in the persistence of IBS symptoms, reversal of long-standing afferent sensitization suggests a novel and highly desirable means of improving the management of pain and hypersensitivity in IBS. Moreover, because linaclotide has low bioavailability and its site of action is localized to GC-C in the epithelial layer of the intestine (Busby et al., 2010), undesirable effects in the CNS are unlikely, thus representing a novel and efficacious approach to managing the abdominal pain experienced by patients with IBS-C.

The mechanisms by which cGMP attenuates afferent responses to stretch and reverses sensitization of $\mathrm{M} / \mathrm{M}$ afferents were not explored in the current study and require further inves- tigation. Canonical mechanisms that involve intracellular cGMP include: (1) cGMP activation of cyclic nucleotide-gated ion channels to dampen neural excitability, (2) pathways associated with protein kinase $\mathrm{G}$ that are downstream of cGMP signaling, and (3) cGMP-regulated phosphodiesterases (PDE2 and PDE3). It also has been reported that extracellular cGMP could modulate neuronal functions (e.g., inhibition of kainate autoreceptors in cerebellar neurons; Cervetto et al., 2010). Given the lack of evidence for active transport of cGMP from the extracellular space into the cytosol, we speculate that the modulation of colorectal afferent excitability by cGMP occurs at an extracellular site.

We further validated the role of cGMP in the attenuation of responses of stretch-sensitive colorectal afferents through activation of colorectal GC-C by the endogenous ligand UGN-A, which was 300 - to 1000 -fold more potent than cGMP. UGN-A fully replicated the effects of cGMP. Importantly, perfusion of the colorectum with probenecid, a nonselective anion transport inhibitor known to block the extrusion of cGMP (Sager, 2004), abolished the effects of UGN-A on responses of M/M afferents to stretch, strongly implying that extracellular cGMP is required for the action of GC-C agonists. This is further supported by our in vitro studies on cultured intestinal T84 cells, which express endogenous GC-C; application of UGN-A, but not the isomeric UGN-B peptide or calcitonin, induced concentration-dependent release of cGMP in T84 cell lysates, an indicator of intracellular cGMP content. Consistent with other results here, the release of UGN-A-stimulated cGMP into the T84 cell supernatant was dose dependently attenuated by probenecid. We are aware of other pharmacological effects of probenecid, including inhibition of intestinal smooth muscle tone (Mihara et al., 2010) and TRPV2 channel activation (Bang et al., 2007). However, in the present study colorectal compliance was unaffected by probenecid, perhaps due to the presence of an L-type calcium channel blocker in the Krebs' solution perfusing the colorectum. The reduced afferent drive affected by GC-C activators like uroguanylin is evident from our current study. In a related report, abdominal contractions in response to colorectal distension in naïve rats were unaffected by oral administration of the GC-C agonist linaclotide (Eutamene et al., 2010); linaclotide, however, did attenuate colorectal hypersensitivity after colorectal inflammation and in two models of stress-induced hypersensitivity, consistent with findings here relative to afferent fiber sensitization by IS and zymosan. Clearly, GC-C activation attenuates colorectal mechanical hypersensitivity, and whether basal mechanosensitivity is also affected remains to be resolved.

In summary, we systematically investigated the effects of cGMP on mechanosensory encoding of PN colorectal afferents. cGMP significantly reduced the encoding functions of LT $(<68$ $\mathrm{mN}$ ) muscular and $\mathrm{M} / \mathrm{M}$ afferents to stretch whereas serosal and mucosal afferents were not affected. HT $(>68 \mathrm{mN})$ muscular and $\mathrm{M} / \mathrm{M}$ afferents both exhibited reduced responses to stretch following $10 \mu \mathrm{M} \mathrm{cGMP}$ application. Acute sensitization of $\mathrm{M} / \mathrm{M}$ and muscular afferents by an inflammatory soup was inhibited by cGMP, although at different concentrations. cGMP also reversed the persistent sensitization of $\mathrm{M} / \mathrm{M}$ afferents recorded from colorectums taken from zymosan-treated, behaviorally hypersensitive mice. To establish that the effects of GC-C activation involve colorectal cGMP, we demonstrated that blocking the release of cGMP with probenecid abolished the effect of the endogenous GCCA uroguanylin on $\mathrm{M} / \mathrm{M}$ afferents. These results suggest that activation of GC-C attenuates responses to stretch of (principally) $\mathrm{M} / \mathrm{M}$ afferents, blocking their acute sensitization and reversing persistent sensitization via synthesis and release of cGMP. 


\section{References}

Bang S, Kim KY, Yoo S, Lee SH, Hwang SW (2007) Transient receptor potential V2 expressed in sensory neurons is activated by probenecid. Neurosci Lett 425:120-125. CrossRef Medline

Basu N, Arshad N, Visweswariah SS (2010) Receptor guanylyl cyclase C (GC-C): regulation and signal transduction. Mol Cell Biochem 334:6780. CrossRef Medline

Bharucha AE, Linden DR (2010) Linaclotide- a secretagogue and antihyperalgesic agent- what next? Neurogastroenterol Motil 22:227-231. CrossRef Medline

Blackshaw LA, Brookes SJ, Grundy D, Schemann M (2007) Sensory transmission in the gastrointestinal tract. Neurogastroenterol Motil 19:1-19. CrossRef Medline

Bouin M, Plourde V, Boivin M, Riberdy M, Lupien F, Laganière M, Verrier P, Poitras P (2002) Rectal distention testing in patients with irritable bowel syndrome: sensitivity, specificity, and predictive values of pain sensory thresholds. Gastroenterology 122:1771-1777. CrossRef Medline

Brierley SM, Jones RC 3rd, Gebhart GF, Blackshaw LA (2004) Splanchnic and pelvic mechanosensory afferents signal different qualities of colonic stimuli in mice. Gastroenterology 127:166-178. CrossRef Medline

Bryant AP, Busby RW, Bartolini WP, Cordero EA, Hannig G, Kessler MM, Pierce CM, Solinga RM, Tobin JV, Mahajan-Miklos S, Cohen MB, Kurtz CB, Currie MG (2010) Linaclotide is a potent and selective guanylate cyclase $\mathrm{C}$ agonist that elicits pharmacological effects locally in the gastrointestinal tract. Life Sci 86:760-765. CrossRef Medline

Busby RW, Bryant AP, Bartolini WP, Cordero EA, Hannig G, Kessler MM, Mahajan-Miklos S, Pierce CM, Solinga RM, Sun LJ, Tobin JV, Kurtz CB, Currie MG (2010) Linaclotide, through activation of guanylate cyclase $\mathrm{C}$, acts locally in the gastrointestinal tract to elicit enhanced intestinal secretion and transit. Eur J Pharmacol 649:328 -335. CrossRef Medline

Busby RW, Kessler MM, Bartolini WP, Bryant AP, Hannig G, Higgins CS, Solinga RM, Tobin JV, Wakefield JD, Kurtz CB, Currie MG (2013) Pharmacologic properties, metabolism, and disposition of linaclotide, a novel therapeutic peptide approved for the treatment of irritable bowel syndrome with constipation and chronic idiopathic constipation. J Pharmacol Exp Ther 344:196-206. CrossRef Medline

Cervetto C, Maura G, Marcoli M (2010) Inhibition of presynaptic releasefacilitatory kainate autoreceptors by extracellular cyclic GMP. J Pharmacol Exp Ther 332:210-219. CrossRef Medline

Chey WD, Lembo AJ, Lavins BJ, Shiff SJ, Kurtz CB, Currie MG, MacDougall JE, Jia XD, Shao JZ, Fitch DA, Baird MJ, Schneier HA, Johnston JM (2012) Linaclotide for irritable bowel syndrome with constipation: a 26week, randomized, double-blind, placebo-controlled trial to evaluate efficacy and safety. Am J Gastroenterol 107:1702-1712. CrossRef Medline

Eutamene H, Bradesi S, Larauche M, Theodorou V, Beaufrand C, Ohning G, Fioramonti J, Cohen M, Bryant AP, Kurtz C, Currie MG, Mayer EA, Bueno L (2010) Guanylate cyclase C-mediated antinociceptive effects of linaclotide in rodent models of visceral pain. Neurogastroenterol Motil 22:312-e384. CrossRef Medline

Feng B, Gebhart GF (2011) Characterization of silent afferents in the pelvic and splanchnic innervations of the mouse colorectum. Am J Physiol Gastrointest Liver Physiol 300:G170-G180. CrossRef Medline

Feng B, Brumovsky PR, Gebhart GF (2010) Differential roles of stretchsensitive pelvic nerve afferents innervating mouse distal colon and rectum. Am J Physiol Gastrointest Liver Physiol 298:G402-G409. CrossRef Medline

Feng B, Kiyatkin ME, La J-H, Gebhart GF (2012a) Cyclic guanylate monophosphate (cGMP) attenuates responses and sensitization of mouse colorectal afferents. Gastroenterology 142 [Suppl 1]:S-698. CrossRef

Feng B, La JH, Schwartz ES, Gebhart GF (2012b) Neural and neuroimmune mechanisms of visceral hypersensitivity in irritable bowel syn- drome. Am J Physiol Gastrointest Liver Physiol 302:G1085-G1098. CrossRef Medline

Feng B, La JH, Schwartz ES, Tanaka T, McMurray TP, Gebhart GF (2012c) Long-term sensitization of mechanosensitive and -insensitive afferents in mice with persistent colorectal hypersensitivity. Am J Physiol Gastrointest Liver Physiol 302:G676-G683. CrossRef Medline

Hughes PA, Brierley SM, Martin CM, Brookes SJ, Linden DR, Blackshaw LA (2009) Post-inflammatory colonic afferent sensitisation: different subtypes, different pathways and different time courses. Gut 58:1333-1341. CrossRef Medline

Johnston JM, Kurtz CB, Macdougall JE, Lavins BJ, Currie MG, Fitch DA, O’Dea C, Baird M, Lembo AJ (2010) Linaclotide improves abdominal pain and bowel habits in a phase IIb study of patients with irritable bowel syndrome with constipation. Gastroenterology 139:1877-1886.e2. CrossRef Medline

Jones RC 3rd, Xu L, Gebhart GF (2005) The mechanosensitivity of mouse colon afferent fibers and their sensitization by inflammatory mediators require transient receptor potential vanilloid 1 and acid-sensing ion channel 3. J Neurosci 25:10981-10989. CrossRef Medline

Jones RC 3rd, Otsuka E, Wagstrom E, Jensen CS, Price MP, Gebhart GF (2007) Short-term sensitization of colon mechanoreceptors is associated with long-term hypersensitivity to colon distention in the mouse. Gastroenterology 133:184-194. CrossRef Medline

Kyloh M, Nicholas S, Zagorodnyuk VP, Brookes SJ, Spencer NJ (2011) Identification of the visceral pain pathway activated by noxious colorectal distension in mice. Front Neurosci 5:16. Medline

Livak KJ, Schmittgen TD (2001) Analysis of relative gene expression data using real-time quantitative PCR and the 2(-Delta Delta $\mathrm{C}(\mathrm{T})$ ) method. Methods 25:402-408. CrossRef Medline

Lucas KA, Pitari GM, Kazerounian S, Ruiz-Stewart I, Park J, Schulz S, Chepenik KP, Waldman SA (2000) Guanylyl cyclases and signaling by cyclic GMP. Pharmacol Rev 52:375-414. Medline

Mihara H, Boudaka A, Shibasaki K, Yamanaka A, Sugiyama T, Tominaga M (2010) Involvement of TRPV2 activation in intestinal movement through nitric oxide production in mice. J Neurosci 30:16536-16544. CrossRef Medline

Rao S, Lembo AJ, Shiff SJ, Lavins BJ, Currie MG, Jia XD, Shi K, MacDougall JE, Shao JZ, Eng P, Fox SM, Schneier HA, Kurtz CB, Johnston JM (2012) A 12-week, randomized, controlled trial with a 4-week randomized withdrawal period to evaluate the efficacy and safety of linaclotide in irritable bowel syndrome with constipation. Am J Gastroenterol 107:1714-1724; quiz p.1725. Medline

Sager G (2004) Cyclic GMP transporters. Neurochem Int 45:865-873. CrossRef Medline

Swenson ES, Mann EA, Jump ML, Witte DP, Giannella RA (1996) The guanylin/STa receptor is expressed in crypts and apical epithelium throughout the mouse intestine. Biochem Biophys Res Commun 225:1009-1014. CrossRef Medline

Verne GN, Robinson ME, Vase L, Price DD (2003) Reversal of visceral and cutaneous hyperalgesia by local rectal anesthesia in irritable bowel syndrome (IBS) patients. Pain 105:223-230. CrossRef Medline

Verne GN, Sen A, Price DD (2005) Intrarectal lidocaine is an effective treatment for abdominal pain associated with diarrhea-predominant irritable bowel syndrome. J Pain 6:493-496. CrossRef Medline

Zagorodnyuk VP, Brookes SJ, Spencer NJ (2010) Structure-function relationship of sensory endings in the gut and bladder. Auton Neurosci 153: 3-11. CrossRef Medline

Zhou Q, Price DD, Verne GN (2008) Reversal of visceral and somatic hypersensitivity in a subset of hypersensitive rats by intracolonic lidocaine. Pain 139:218-224. CrossRef Medline 